\title{
THORACOSCOPIC TREATMENT OF DIAPHRAMMATIC HERNIA: A CASE REPORT
}

\section{Sica M, E. Cerchia., F. Molinaro, M. Pavone, E. Bindi, M. Messina}

\author{
The Section of Pediatric Surgery, Department of Medical Sciences, Surgery and Neuroscience, \\ University of Siena, Siena, Italy.
}

\begin{abstract}
Congenital diaphragmatic hernia (CDH) occurs in 1 of every 2000 to 5000 live births and accounts for $8 \%$ of all major congenital anomalies. $\mathrm{CDH}$ is a diagnosis with multiple, mostly unknown origin and its clinical presentation is highly variable. We are presenting a case of CDH hernia in a neonate, whith prenatal diagnosis at 32 week without any other associated malformation, that was repaired successfully using a staged thoracoscopic approach. Bochdalek described CDH in 1848, and the first surgical repair in a child was reported in 1905. Silen et al first reported thoracoscopic repair in 1995, but the reported world experience includes very few cases in neonates.
\end{abstract}

Key words: Congenital diaphragmatic hernia, thoracoscopic approach, high frequency oscillatory ventilation.

\section{INTRODUCTION}

Congenital diaphragmatic hernia $(\mathrm{CDH})$ occurs approximately in 1 of every 2000 to 5000 live births and accounts for $8 \%$ of all major congenital anomalies. Medical and surgical management of these patients has changed over the patients has changed over tha past several decades. "Gentle ventilation" strategies, high-frequency oscillatory ventilation (HFOV), and other methods of supportive care have changed the intensive care management of $\mathrm{CDH}[1,2,3]$. Parallel with this intensive care improvements has been a paradigm shift over the past 20 years from emergent operation to elective repair $[4,5]$. The combination of innovations in intensive care and elective operation has resulted in an opportunities to use minimally invasive surgery (MIS) to the correction of CDH. In other thoracic conditions, thoracoscopy has been suggested to have significant advantages over the traditional open approaches. These benefits may include a decrease in the pain and incisional morbidity of a thoracotomy (i.e. subsequent scoliosis, chest deformities, and shoulder muscle girdle weakness), reduced surgical stress and immunologic derangement, faster recovery and shorter hospitalizations [6-14]. Very little is Known about the outcomes in selected patients receiving a thoracoscopic approach, compared with a laparoscopic and with an open repair.

This report decribes a case of thoracic treatment of a postero-lateral diaphragmatic hernia.

\section{CLINICAL PRESENTATION}

A $3190 \mathrm{~kg}$ male neonate was delivered with a gestational age $38 * 2$ /weeks. A prenatal diagnosis of $\mathrm{CDH}$ with ultrasound was made at 32 weeks gestation, with both lungs present and in the absence of other malformations. At the birth the newborn was intubated as the protocol. Upon admission to the neonatal intensive care unit haemoglobin $\mathrm{O} 2$ saturation was $78 \%$, cardiac frequency 108, peak inspiratory pressures 23 and high frequency oscillatory ventilation and inhaled nitric oxide were initiated, including sedation and plasma infusion.

Chest $\mathrm{x}$-ray showed shift of the mediastinal structures to the right side and elevated left hemidiaphragms (Figure 1). The neonate required moderate mechanical ventilator support.

Operative repair was performed when the patient demonstrated both hemodynamic and pulmonary stability. The decision to perform MIS was supported by the surgeon because thorax $\mathrm{x}$-ray showed the nasogastric tube in the abdomen so the presence of the stomach under the diaphragm and there was the absence of pulmonary hypertension.

Thoracoscopir repair was performed with the patient in the lateral decubitus with the affected side elevated. The patient is placed on a stack of towels with the position of the head slightly lower on a cushion (Figure 2). A $5 \mathrm{~mm}$ port is placed subscapularly. A pneumothorax is created by gradual insufflations of carboc dioxide to a pressure of $4-6 \mathrm{mmHg}, 0.5 \mathrm{l} / \mathrm{min}$. A $5 \mathrm{~mm}$ telescope is

Correspondence to:

Prof. Mario Messina

Division of Pediatric Surgery, Dept of Medical Sciences, Surgery and Neuroscience, University of Siena "Le Scotte"

Viale Bracci 16, 53100 Siena, Italy

Tel.: +39.577.586501; Fax: +39.577.586.174

E-mail: mario.messina@unisi.it 
inserted through the subscapular port. Two additional $3 \mathrm{~mm}$ working ports are placed under direct vision; one on the anterior axillary line at the $4^{\text {th }}$ intercostals space and other one on the posterior axillary line in the $5^{\text {th }}$ intercostals space. Herniated organs (small bowel, colon and spleen) are gently reduced into the abdomen through the defect. After reduction of hernia contents, insufflations pressure was decreased to $4 \mathrm{mmHg}$, and a transparietal stitch is positioned at half of the defect in order to facilitate the closure. Primary repair was per-

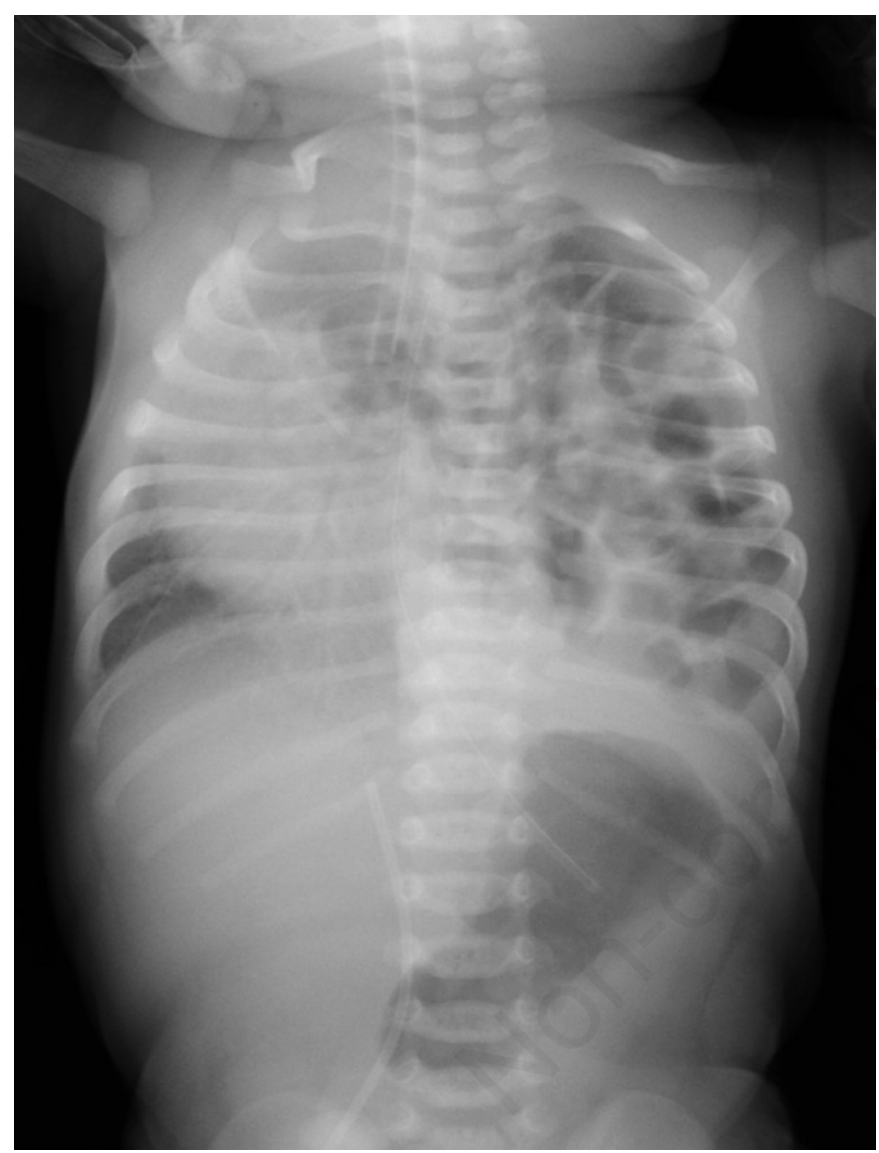

Figure 1. Preoperative X-Ray chest showing left side diaphragmatic hernia.

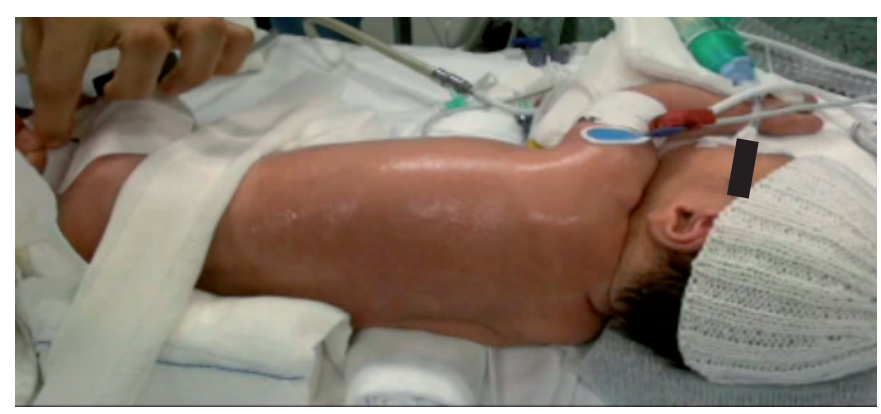

Figure 2. Position of the patient. formed with interrupted 3/0 Vicryl sutures, with most lateral anchorated stitches to the rib. At the end drainage was positioned above the diaphragm (Video 1).

Chest tube was placed wich was removed in fourth postoperative day. Postoperative chest film revealed satisfactory result of the left sided repair without sign of recurrence (Figure 3).

Postoperatively, the patient was estubated on the fourth day. The follow-up was of 6 months.

He grows and feeds regularly. At the $\mathrm{x}$-ray at three months, he has no sign of recurrence.

\section{DISCUSSION}

Congenital diaphragmatic hernia is the result of incomplete closure of the normal pleuroperitoneal canal during fetal development. Recently, there have been increasing reports of the use of thoracoscopy for the repair of CDH. Minimally invasive surgery (MIS) for infants and children continues to grow. MIS was introduced first treatment of congenital diaphragmatic hernia $(\mathrm{CDH})$ in 1995; Silen et al. [15] used thoracoscopy, while Van der Zee and Bax [16] used laparoscopy. However, most pediatric surgeons have started to apply MIS to CDH because of associated fragile respiratory status and pulmonary hypertension $(\mathrm{PH})$ - Neverthless, thoracoscopic repair under high-frequency oscillatory ventilation (HFOV) [17] or after extracorporeal membrane oxygenation (ECMO) therapy have been reported recently, and MIS appears to be gaining added acceptance for $\mathrm{CDH}$ repair without any fixed selection criteria being established [18-21].

There are few reports about indication for thoracoscopic repair (TR) of CDH. Yang et al. proposed selection criteria for TR from anatomic and physiologic aspects: stomach in the abdomen, minimal ventilator support

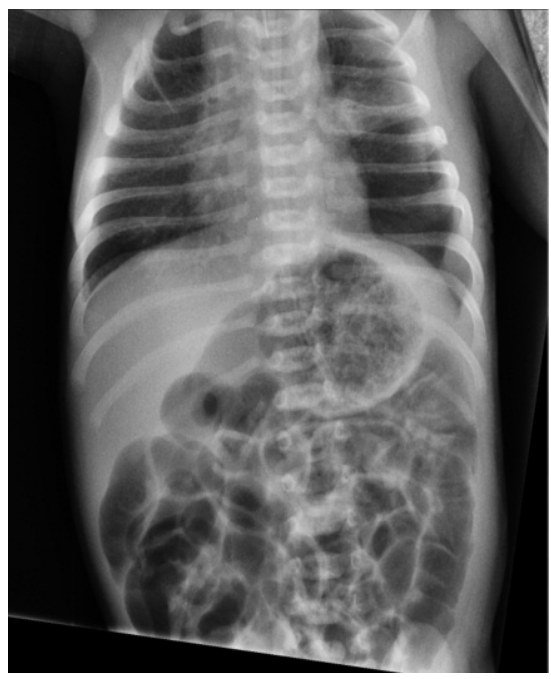

Figure 3. Postoperative X-Ray. 
with low peak inspiratory pressure $(<24 \mathrm{mmHg})$, and no evidence of pulmonary hypertension at the time of surgery. Similar criteria were also proposed by Guner et al., but from our experience this criteria are not contraindications to thoracoscopic treatment in the pulmonary hypertension is controlled even through HFOV may be required.

Our patient corresponded to the Yang criteria so we have practised a thoracoscopic approach.

Another disadvantages was that the recurrence rate was significantly higher in the TR. The cause of this is not known, but certain technical factors may contribute to it. As in other minimally invasive operations, the operative field is magnified. This may lead to overestimating the space between sutures on the diaphragm. A second explanation may be the tension placed on the sutures during the repair. Tension is difficult to disperse among several sutures when tying knots thoracoscopically, and an excessive amount may be placed on each suture during the repair. A third explanation may be inadequate mobilization of the rim of diaphragm. During the open procedure, the diaphragm is routinely "unfurled", exposing a larger area of posterior diaphragm to allow suture placement for repair. Another possible explanation is the learning curve of this new operation [22].

In our case, to reduce the risk of recurrence, we placed a transparietal point in order to show the defect especially in its postero-lateral portion of the diaphragm because this is the most difficult point to close correctly, performing thoracoscopy. And finally, we have used Vycril points which have the advantage of having a greater stability with a reduced possibility damnage the edge of the defect.

Moreover a number of surgeons have used laparoscopy to repair CDH [23-26]. However, the thoracoscopic approach has some advantages compared to the laparoscopic approach. In the laparoscopic approach was difficult to bring the spleen back into the abdominal cavity. The sutures could be difficult to place because the intestine is an obstacle to observe the diaphragmatic defect. With thoracoscopic approach, one could directly visualize the hernia and the organs, and gently push them down into the abdominal cavity. Suturing of the hernia defect was performed easily because there was unobstructed access to the posterior lateral defect. Also, the insufflations facilitates the return of the hernia contents into the abdominal cavity. Thoracoscopy is better approach when compare with an open procedure because muscles are not divided; hence, postoperative respiratory function is minimally impaired [27].

\section{CONCLUSIONS}

In conclusion, thoracoscopic repair for $\mathrm{CDH}$ is feasible and safe in good hands, it could be indicated for se- lective newborn patients as well as for infants and elders. Easy access, minimal trauma, good cosmetic results, and rapid recovery are all important advantages for this thecnique.

More cases and longer follow-up are required tp validate this findings.

This study is limited for the presence of only one patient and the low follow-up. However, the details of the report suggest that careful review and quality control regarding surgical technique are likely to improve outcomes in patient undergoing TR. It is necessary that all surgeons who will approach this new technique have a good learning curve.

\section{REFERENCES}

1. Lao OB, Crouthamel MR, Goldin AB, et al. Thoracoscopic repair of congenital diaphragmatic hernia in infancy. J Laparoendosc $A d v$ Surg Tech A 2010;20:271-6.

2. Weber TR, Kountzman B, Dillon PA, Silen ML. Improved survival in congenital diaphragmatic hernia with evolving therapeutic strategies. Arch Surg 1998;133:498-502.

3. Downard CD, Jaksic T, Garza JJ, et al. Analysis of an improved survival rate for congenital diaphragmatic hernia. J Pediatr Surg 2003;38:729-32.

4. Harting MT, Lally KP. Surgical management of neonates with congenital diaphragmatic hernia. Semin Pediatr Surg 2007;16:109-14.

5. Chiu PP, Sauer C, Mihailovic A, et al. The price of success in the management of congenital diaphragmatic hernia: Is improved survival accompanied by an increase in long-term morbidity? J Pediatr Surg 2006;41:888-92.

6. Fujimoto T, Segawa $O$, Lane GJ, et al. Laparoscopic surgery in newborn infants. Surg Endosc 1999;13:773-7.

7. Goldschlager T, Frawley $G$, Crameri J, et al. Comparison of thoracoscopic drainage with open thoracotomy for treatment of paediatric parapneumonic empyema. Pediatr Surg Int 2005;21:599-603.

8. Kishan S, Bastrom T, Betz RR, et al. Thoracoscopic scoliosis surgery affects pulmonary function less than thoracotomy at 2 years postsurgery. Spine 2007;32:453-8.

9. Novitsky $Y W$, Litwin DE, Callery MP. The net immunologic advantage of laparoscopic surgery. Surg Endosc 2004;18:1411-9.

10. Sylla P, Kirman I, Whelan RL. Immunological advantages of advanced laparoscopy. Surg Clin North Am 2005;85:1-18.

11. Tolg C, Abelin K, Laudenbach $V$, et al. Open versus thorascopic surgical management of bronchogenic cysts. Surg Endosc 2005;19:77-80.

12. Winslow ER, Brunt LM. Perioperative outcomes of laparoscopic versus open splenectomy: a meta-analysis with an emphasis on complications. Surgery 2003;134:647-53.

13. Rothenberg SS, Pokorny WJ. Experience with a total musclesparing approach for thoracotomies in neonates, infants, and children. $J$ Pediatr Surg 1992;27:1157-60.

14. Bal S, Elshershari H, Celiker R, Celiker A. Thoracic sequels after thoracotomies in children with congenital cardiac disease. Cardiol Young 2003;16:264-7.

15. Silen ML, Canvasser DA, Kurkchubasche AG, et al. Video-assisted thoracic surgical repair of a foramen of Bochdalek hernia. Ann Thorac Surg 1995;60:448-50.

16. Van der Zee, Bax NM. Laparoscopic repair of congenital diaphragmatic hernia in a 6-month-old child. Surg Endosc 1995;9:1001-3.

17. Liem NT, Dien TM, Ung NQ. Thoracoscopic repair in the neonatal intensive care unit for congenital diaphragmatic hernia during 
high-frequency oscillatory ventilation. J Laparoendosc Adv Surg Tech A 2010;20:111-4.

18. Kim AC, Bryner BS, Akay B, et al. Thoracoscopic repair of congenital diaphragmatic hernia in neonates: lessons learned. $J$ Laparoendosc Adv Surg Tech A 2009;19:575-9.

19. Yang EY, Allmendinger N, Johnson SM, et al. Neonatal thoracoscopic repair of congenital diaphragmatic hernia: selection criteria for successful outcome. J Pediatr Surg 2005;40:1369-75.

20. Guner YS, Chokshi N, Arenda A, et al. Thoracoscopic repair of neonatal diaphragmatic hernia. J Laparoendosc Adv Surg Tech A 2008; 18:875-80.

21. Cho SD, Krishnaswami S, Mckee JC, et al. Analysis of 29 consecutive thoracoscopic repairs of congenital diaphragmatic hernia in neonates compared to historical controls. J Pediatr Surg 2009;44:80-6.

22. Gander JW, Fisher JC, Gross ER, et al. Early recurrence of congen- ital diaphragmatic hernia is higher after thoracoscopic than open repair: a single institutional study. J Pediat Surg 2011;46:1303-8.

23. Van der Zee DC, Bax NM. Laparoscopic repair of congenital diaphragmatic hernia in a six-month-old child. Surg Endosc 1995;9:1001-3.

24. Taskin M, Zengin K, Unal E, et al. Laparoscopic repair of congenital diaphragmatic hernias. Surg Endosc 2002;16:869.

25. Lima $M$, Lauro $V$, Donum $M$, et al. Laparoscopic surgery of diaphragmatic diseases in children: our experience with five cases. Eur J Pediatr Surg 2001;11:377-81.

26. Shah AV, Shah AA. Laparoscopic approach to surgical management of congenital diaphragmatic hernia in the newborn. J Pediatr Surg 2002;37:548-50.

27. Becmeur F, Jamali RR, Moog R, et al. Thoracoscopic treatment for delayed presentation of congenital diaphragmatic hernia in the infant. Surg Endosc 2001;15:1163-6. 